\title{
The Role of Internal and External Sources of Knowledge in the Product Lifecycle in Biotechnology Sector
}

\author{
Elham Tayaran ${ }^{1}$ and Andrea Schiffauerova ${ }^{2}$ \\ ${ }^{1}$ Concordia University, Department of Mechanical and Industrial Engineering, Montreal, \\ Quebec, Canada H3G 2W1 \\ e_tayar@encs.concordia.ca \\ ${ }^{2}$ Concordia University, Concordia Institute for Information Systems Engineering, Montreal, \\ Quebec, Canada H3G 2W1 \\ andrea@ciise.concordia.ca
}

\begin{abstract}
In today's highly competitive environment, addressing product management throughout its lifecycle in a more comprehensive way has become a necessity. A lot of attention has been paid to the decisions taken within the early stages of product development, which can have a great effect on the entire product life. Knowledge provides a firm with valuable and unique capabilities essential for the successful product development during its early stages. Therefore, a firm must understand how to manipulate its various knowledge sources to enhance its own performance. This article examines the dynamic behavior of the interactions and feedback mechanisms between different sources of knowledge. Using System Dynamics simulation we identify the impacts of a firm's innovation policy on its innovative performance later in the lifecycle, and find that, in general, focusing on the exploitation of external knowledge sources is a suitable strategy, but various internal factors should be considered as well.
\end{abstract}

Keywords: Product lifecycle management, product lifecycle knowledge management, innovation process, biotechnology, nonlinear dynamic system.

\section{$1 \quad$ Introduction}

Product lifecycle management (PLM) is an all-encompassing approach for innovation, new product development and introduction from ideation to end of life [1]. It spans from concept to end of life of a product [2], i.e. from its "cradle to grave" (Stark, 2005). Given the importance of knowledge and information in the knowledgeintensive industries, Ameri and Dutta (2005) have argued that PLM is really a knowledge management solution, because PLM "is all about knowledge management". Unlike Product Data Management (PDM) systems which focus on managing data, the core of PLM process supports the capturing, organizing and reusing the knowledge throughout the product lifecycle (Ameri and Dutta, 2005). Research indicates that in a typical organization, only $4 \%$ of organizational knowledge is available in a structured and reusable format where the rest is either unstructured or resides in peoples' minds (Rasmus, 2002). Since most of the knowledge available in an organization during the 
product lifecycle is thus accessible only in an unstructured form, careful knowledge management is needed to govern the creation, dissemination, and utilization of this knowledge.

Knowledge is a critical element in the innovation process. A lot of attention has been recently paid to its first less formal and less structured phase, the early stage of innovation, also called front end of innovation (FFE), whose role is to produce ideas for new product concepts as well as to select the ideas that fit with the firm's business strategy. The importance of FFE in the success of the innovation process has been emphasized by many studies (Kim and Wilemon, 2002; Khurana and Rosenthal, 1998; Brem and Voigt, 2009). It was also claimed that insufficient groundwork in the FFE as well as delayed FFE processes could lead to failures in the development or commercialization processes (Kim and Wilemon, 2002). Therefore, the knowledge created, disseminated and utilized during the FFE phase and the related decisions made in the FFE stage affect the entire product lifecycle. Project delays, increased time-to-profit to get return from market, budget escalation problems, and various performance issues have often been related to little management attention during the FFE process (Herstatt and Verworn, 2001).

The new knowledge necessary for the early stage of innovation process in biotechnology can be generated by two alternative means: On the one hand, an organization's own R\&D creates the new knowledge with internal sources based on the experience gained from its own in-house research and the information gathered by organizational learning throughout its research projects. On the other hand, external knowledge can be acquired outside the organization, for instance in competitive markets or through inter-organizational linkages. In fact, PLM systems can greatly facilitate effective collaboration among different participants in product value chain, including reaching, recording and reviewing ideas from internal and external sources such as suppliers, vendors, customers, competitors and employees (Awazu et al., 2009). In order to leverage knowledge properly, it is necessary to understand its nature accurately, as different sources will provide knowledge with different impacts on the innovation process and the entire product lifecycle. Internal sources of knowledge can supply firms with radical, breakthrough innovations, but the related innovative process is more iterative, time consuming, expensive and risky. External sources of knowledge, on the contrary, are cheaper and less risky, but at the same time, the external knowledge cannot generate a competitive advantage on its own, since it is easily available to rivals (GarciaMuina et al., 2009). Gaining external knowledge through collaborations allows individual firms to advance their scientific discoveries when there is a lack of specific resources or expertise. However, a significant strategic commitment to R\&D is critical, especially for knowledge-intensive industries. These two sources hence complement each other, but one can influence the performance of the other one. They could affect not only the whole innovation process, but also the entire product lifecycle.

The decisions as to the most appropriate combination of knowledge sources are quite complex and can have a great effect on the outcomes of technology-oriented companies. For instance, in biotechnology, which is highly knowledge- and researchintensive, the importance of this decision is even more pronounced, and thus it attracted our attention. The innovation process in biotechnology is usually presented as 
a set of sequential activities (Hall and Baghchi-Sen, 2002). This linear model demonstrates neither the interactions of various determinants of innovation nor their influence on the firm's performance (Hall and Baghchi-Sen, 2002; Khilji et al., 2006). However, the real innovation process is more complex and iterative, and various interactions thus need to be investigated in the PM context in order to reveal all of its complexities and interdependencies.

The article' main objective is to improve the understanding of the dynamics of the technological innovation within the PLM context, through the design of the dynamic model representing the early stage of the innovation process and through the subsequent simulation of this model. This will allow us to evaluate the factors that have an impact on the innovation process and to investigate those organizational policies that can enhance the outcome of this process. A special attention is paid to the analyzing the right balance between adopting internal vs. external sources of knowledge in the early stage of innovation.

This article is structured as follows. Section 2 reviews the related literature in innovation, with a special focus on the front end of innovation and formulates the research questions. The details of model variables and their relationships are introduced in Section 3. Accordingly, the dynamics of the model, the causal diagram and the main findings are presented in Section 4. Section 5 presents a discussion on the findings while Section 6 concludes the work.

\section{Front End of Innovation: Models and Theories}

\subsection{Theoretical Foundation}

The front end of innovation (FFE) relates to such activities as generation of ideas, initial screening, preliminary evaluation, and concept evaluation. These activities are highly interconnected and cyclically crossing each other. While the early stage activities significantly affect the outcome of innovation process, the related research was initially limited to one factor, the 'quality of predevelopment activities'. However, since the 90', more detailed studies have been carried out to shed some light on the early phase of innovation. Theoretical consideration (e.g. Reid and de Brentani, 2004; Zhang and Doll, 2001) and qualitative studies (e.g. Koen et al., 2001; Khurana and Rosenthal, 1998) are the two groups comprising the majority of the early stage of innovation literature (Verworn, 2009). Various models were proposed, among which the more commonly cited ones are: Stage gate process as one of the most commonly applied linear models (Cooper, 1990) and the New Concept Development model (NCD) (Koen et al., 2001) which is one of the non-linear and iterative process models.

The extensive review of related literature reveals various process models of the early stage of innovation that provide a firm with a better understanding of the activities and roles involved in the early stage of innovation. However, the application of these models has been limited to investigating the innovation processes within the traditional industries that mainly introduce incremental innovation, while the biotechnology industry has been overlooked. Therefore, further evaluation is required to 
extend the understanding of the early phase of innovation beyond the traditional field of inquiry. The innovation process in biotechnology is characterized by high R\&D cost, global competition, rapid changes, long development time as well as considerable degree of uncertainties. Innovation process in biotechnology generally has been presented by a sequence of activities that transform an idea into a commercial product, however, the linear representation cannot demonstrate a feedback mechanism and interactions of various elements in the process (Hall and Baghchi-Sen, 2002; Khilji et al., 2006).

\subsection{Significant Elements of the Early Stage of Innovation in Biotechnology}

\section{Sources of Knowledge}

The new knowledge in biotechnology can be generated by two alternative means: the firm's own R\&D (internal sources) at one extreme, and the acquisition of knowledge in competitive markets and the inter-organizational linkages (external sources) at the other. Internal sources can be defined as conducting internal research and development activities (R\&D) and the experience acquired by performing organizational process and studying via research projects (Nieto Antolin, 2001). External sources can refer to any type of accumulation and incorporation of technological knowledge in which a third party is involved. The direct purchase of technology, technology incorporated in machinery required, licensing contract, university-industry linkages and relationships among firms are examples of external knowledge (Todtling and Trippl, 2007; Garcia-Muina et al., 2009). Making collaborations allows individual firms to advance their scientific discoveries when there is a lack of specific resources or expertise. Through external sources, the firm is able not only to obtain new knowledge that could be directly exploited in various research projects, but it can also gain enough new information to constantly re-evaluate its projects' portfolio (Deeds, 2001). However, a significant strategic commitment to $R \& D$ is critical for a knowledge intensive technology, such as biotechnology, in order to achieve the competencies required to succeed, despite the level of technology developed in-house or accessed through external resources.

\section{Absorptive Capacity}

Even though the external knowledge is easily available to competitors, all the firms cannot gain an equal benefit from it. The concept of absorptive capacity brings attention to the fact that when knowledge exists outside of the firm, even if it is in public domain, it cannot be effortlessly and freely absorbed by all the firms. Instead, investing in particular activities, such as in-house research is required to allow firms to identify, assimilate, transform and exploit outside knowledge more effectively (Cohen and Levinthal, 1990). Several activities that may contribute to the creation of a firm's absorptive capacity have been identified in literature. Cohen and Levinthal (1990) considered R\&D investments as an important factor to their conceptualization of absorptive capacity. 


\section{Funding}

Funding is considered to be a backbone of biotechnology, since firms spend huge amount of money on research and development activities (Hall and Baghchi-Sen, 2002). The funding can be provided to a biotechnology firm from different investment sources. Government research funds, venture capital firms, capital from angel investors and initial public offerings are all of the major sources for financing a biotechnology firm. Nevertheless, due to the long term development process, it is difficult for biotechnology firms to attract venture capital which could carry them through the entire innovation process.

\section{R\&D Intensity}

The amount of investment in R\&D also differs based on a firm's commitment to research and development activities. This is represented in the literature by R\&D intensity, defined as the percentage of a firm's revenues spent on research and development (Hall and Baghchi-Sen, 2007). High R\&D intensity firms are mainly characterized by low revenue and focus more on the earlier stages of innovation, which usually involve heavy R\&D investments and access to university research. Low R\&D intensity firms mostly focus on the later stage of the innovation process, which includes commercialization of the product or process (Hall and Baghchi-Sen, 2007).

\section{Dynamics of the Model}

Review of the literature reveals that the critical factors for the achievement of a successful innovation process are the commitment to research and development activities, the use of external knowledge, the partnership with major research institutes, the supply of skilled scientists, and the access to venture capital and government support. Although each aspect is individually significant, their combined utilization creates a complex system that can be hardly controlled without having planned strategies. Complexity here is not meant in terms of the number of components in a system, but as it arises from the interactions among the variables over time. In this regard, managers and policy makers need to know how these factors affect each other, and which strategies improve firm performances the most under various conditions. Accordingly, this study intends to contribute to the knowledge advancement by investigating the factors that enhance innovation performance in biotechnology while using the System Dynamics methodology.

The decision of how to exploit different sources of information for creating innovation resources is not a static decision. To maintain a competitive advantage, a biotech firm must constantly review their previous decisions on the allocation of resources in order to be able to timely react to any changes. A firm also needs to identify different strategies in order to respond to a variety of internal and external conditions. While analytical models in biotechnology innovation (Van Moorsel et al., 2007; Traore, 2004; Kang and Lee, 2008) provide valuable insights into potential factors and drivers contributing to the creation of new knowledge and innovation, they do not provide a temporal understanding of the dynamic nature of policy decisions and feedback mechanisms. 
System Dynamics modeling as a methodology to capture the dynamic decision process was founded by Forrester (1968). The methodology is able to deal with complex systems with nonlinear characteristics by analyzing feedback loops and impact of delay. It also enables assessing quantitative and qualitative variables as well as the existence of a supportive computer-based modeling package (Galanakis, 2006; Dangelico et al., 2010; Garcia et al., 2003).

Using the System Dynamics to analyze the innovation process in the causal graph helped us to portray the relationships among the identified factors in order to illustrate the whole causality of the system. After introducing the relevant factors of the problem we examine the cause and effect relationships among variables and then we identify feedback loops within the system.

\section{Causal Diagram}

Figure 1 shows the main elements of the model. The model describes the relations between the main factors affecting the decision in using internal or external knowledge. The positive (+) and negative signs (-) on the arrows indicate the kind of relationship between the variables in the model. A positive sign means that by increasing or decreasing the independent variable, the dependent one will also increase or decrease, respectively. A negative sign indicates an opposite trend, so the dependent variable will decrease or increase as the independent variable is increased or decreased, respectively.

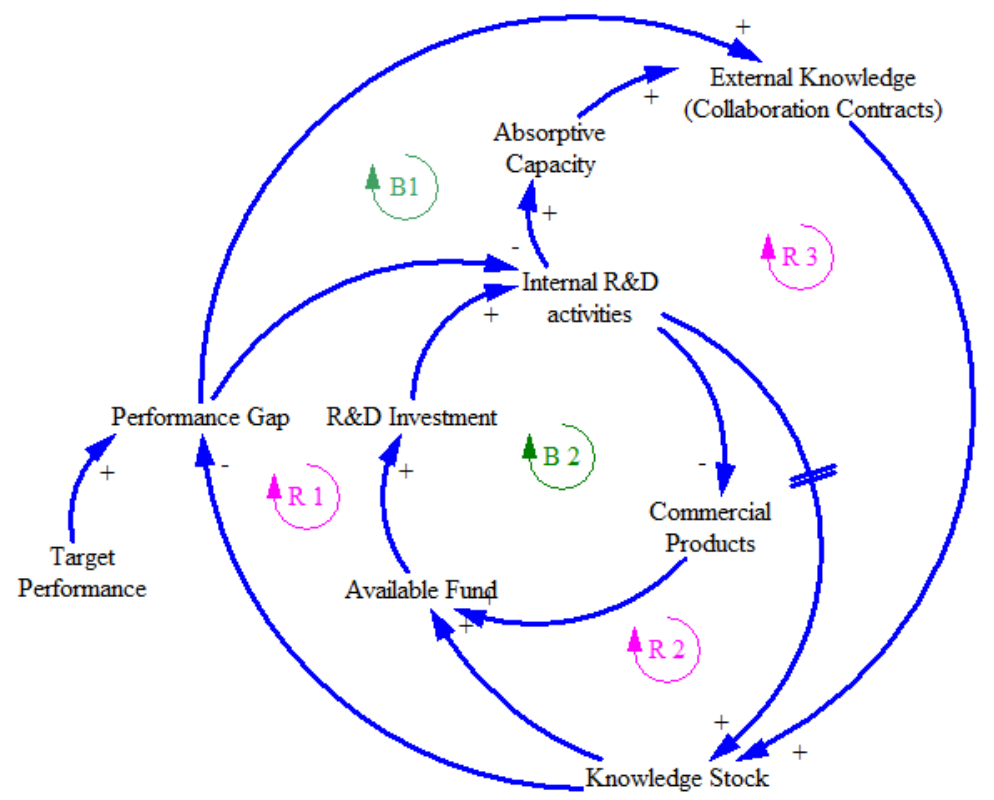

Fig. 1. The causal diagram of the early stage of innovation in biotechnology 
The causal diagram shown in Figure 1 not only demonstrates all the important factors in the FFE stage, but it also represents various conditions that reflect a firm's decision in terms of using a particular source of knowledge. The simulation model and equations (not shown here) were also built based on this causal diagram.

As previously explained, a firm can either create all of its knowledge and resource requirements through internal $\mathrm{R} \& \mathrm{D}$ activities or utilize external resources, such as creating strategic alliances and acquiring knowledge from external parties. Nevertheless, obtaining external knowledge and exploiting it to generate new knowledge largely depends on the ability of a firm to recognize and develop external resources. This ability highlights a very important aspect of organizational learning, defined as absorptive capacity which can be generated through R\&D activities.

In this model, the critical decision of when and to what extent the knowledge should be developed internally or externally is made based on the size of the knowledge Performance Gap (PG). The performance measure is defined by the value of knowledge created in the firm.

$$
\text { PG }(\mathrm{t})=(\text { target knowledge value- actual knowledge value })
$$

The choice of this measure is consistent with the study conducted by Garcia et al. (2003). However, the performance measure used in this paper is not based on the financial performance indicators, such as the return on assets, sales growth or profit margin. These are inappropriate because biotechnology firms do not have any history of profits or earnings due to the long production cycle and the inherent complexity of scientific explorations (De Luca et al., 2010). Instead, the biotechnology firms' value is constrained by intangible assets that the firms possess, and these are represented by their knowledge. Therefore, the performance measure is defined by the value of knowledge created in the firm.

The knowledge created by either source of information, i.e. internal or external, produces distinct values for the firm. Knowledge that is created by internal learning involves more uncertainties, which makes it riskier compared to information that can be achieved through external learning (Garcia-Muina et al., 2009). Nevertheless, knowledge and resources acquired internally are more likely to provide the firm with breakthrough innovations that can lead to the creation of a competitive advantage for the firm (Matusik, 2002; Schroeder et al., 2002, Garcia-Muina et al., 2009).

When the performance gap is zero, an equal amount of funding will be dedicated to each one. A nonlinear relationship is determined and modeled as an S-shaped curve, according to qualitative data derived from the literature

In this model, when the gap is positive, i.e. the knowledge level of the firm falls behind its target, the company tries to close the performance gap with a fast and less risky alternative source of knowledge, which is external knowledge. Consequently, more positive gap leads to the firm concentrating more on the external projects. This focus on the external knowledge acquisition will result in the greater knowledge stock, which finally leads to a decrease in the gap between the target value of knowledge and the actual performance of the firm (See Figure 1, B1 loop). This assumption is made since it is empirically proved that external knowledge gained through collaboration will benefit firms by providing faster results than if the firms get engaged in 
an internal basic research instead (Fabrizio, 2009). However, making collaborative contracts depends on having sufficient absorptive capacity as well. If the firm exceeds its target, then it intends to maintain its competitive advantage among the other firms, and therefore it will concentrate on the internal R\&D activities to introduce a newer and better product to the market (See Figure 1, R1 loop). This allows the firm not only to generate new knowledge, but also to simultaneously enhance its ability to absorb and exploit existing knowledge. This creates our third reinforcing loop, which is called R3 (see Figure 1), and which demonstrates that more investment in internal R\&D leads to an increase in absorptive capacity. On the other hand, focusing more on external resources and less on internal activities leads to a steady decline in the absorptive capacity. However, the slope and the amount of this decrease vary for each firm depending on the firm's skills and number of employees.

As the firm generates more knowledge, it will have more access to the venture capital, because it is expected to license its patents, thereby signaling to the venture capital investors that there is an avenue for further development in which they can invest (Niosi, 2000). By having access to a greater source of funds, the firm is able to spend more on research activities. Therefore, with some delay, the firm's effort leads to an increase in its knowledge stock (See Figure 1, R2 loop).

According to the characteristics of the reinforcing loop, the system is inclined to keep investing in the firm's own R\&D, but the financial resources are limited and the investment in R\&D activities cannot last for the long term. Loop B2 in Figure 1 shows that as the firm invests more in $R \& D$, it will have less money to introduce a new product into the market, which causes a decrease in the available funds and subsequently impacts the amount of investment for future research (Khilji et al., 2006).

Based on the analysis of all the feedback relationships of variables, we define the equations and functions of the interrelationships in order to transform them into a fully formalized model through a System Dynamics software package called Vensim. In this model, simulation methods are employed to investigate the effect of using external knowledge and establishing the strategic alliances on the knowledge performance gap. In the following parts the effect of the gap size, $R \& D$ expenditures and the firm's initial orientation towards different sources of knowledge on the firm's policy decision are examined and the results interpreted.

\section{Discussion}

\subsection{Increase in the Target Knowledge}

The objective of this exercise is to examine how the system reacts to different amounts of increase in the performance target. The target is increased by $10 \%, 30 \%$ and $50 \%$ in the time 8 (quarters) in three sets of runs. The simulation results show that the firm is able to gradually reduce the generated gap. This happens because of the increase in the target by acquiring required knowledge through utilizing external partnerships with other firms and research institutes. However for the higher amount of increase in the target knowledge, this model shows that, for the short term, using external knowledge can reduce the gap, but putting more emphasis on this strategy leads 
to a considerable distance between the actual knowledge of the firm and its desired gap in the long term.

\subsection{The Response of the Gap to the R\&D Cost Changes}

The effectiveness of the external knowledge acquisition strategy cannot only be judged by the amount of increase in the performance target. The same increase of $60 \%$ in the target was tested for both the initial condition (condition of the base case model) and when the R\&D activities cost less for a firm. This is usually the case of large firms, because they have lower average $R \& D$ expenditures due to the economies of scale, which results in a higher return for the firm (Van Moorsel et al., 2007). The simulation results show that, when the cost of R\&D projects is low and their return is high, even for a small increase in the target, external collaboration is not an effective policy and if the firm intends to adopt this policy other parameters should also betaken into account.

\subsection{Resource Allocation between External and Internal}

Finally, the third set of simulation run investigates the effect of the firm's initial policy towards allocation of funds for R\&D activities and acquiring external knowledge. The model is tested for two sets of scenarios: (1) a firm with high R\&D intensity (75\% of its available funds are allocated to in-house research activities); (2) a firm with low R\&D intensity (30\% of its available funds are allocated to in-house research activities).

For the first scenario, the results show that when there is an increase in the target, investing more in the external sources of knowledge for firms with a high R\&D intensity brings fast results, even for a larger performance gap. This can be justified through the concept of absorptive capacity. The firm which had already invested most of its funds in R\&D activities, has accumulated a vast pool of knowledge and hence a high absorptive capacity (AC). This accumulated knowledge and absorptive capacity provide the firm with the capability to exploit the outside knowledge effectively.

For the second scenario, the results show that there is not a significant difference between the initial condition (50\% allocation of fund to R\&D activities) and this scenario. From these results we can infer that when a firm has already spent more than $50 \%$ of its funds on establishing collaborative agreements and acquiring external knowledge, pursuing this strategy cannot be beneficial. However, this strategy is only efficient for small gaps, while for larger gaps, further use of external knowledge leads to an increase in the gap.

\section{Conclusion}

By using System Dynamics to analyze the effect of internal and external sources of knowledge on the innovation process, the article illustrates the critical factors influencing the firm's decisions. The focus is on finding the most suitable combination of the 
two sources of knowledge in order to increase the firm's innovative productivity. Regarding the role each source of knowledge plays in competitive conditions, the main objectives of the research pertain to how the biotechnology firm can maintain the right balance between adopting in house activities vs. building external collaboration and how it can execute its innovation plans while using the appropriate combination of the two different sources of knowledge. Maintaining the proper balance in using the two sources of knowledge will present companies with a new way to identify, organize, manage, and deliver new products or services to the market much faster, better, and cheaper in an integrated way. This is also in line with Product Lifecycle Management (PLM) concept, which enables manufacturing organizations to obtain the greatest competitive advantage by creating better product in less time and at a lower cost while benefiting from collaborative creation, management and the use of product previous knowledge (Ming et al, 2005).

To maintain performance expectations, a firm should utilize distinct strategies for acquiring knowledge depending on the firm's innovative goals and other internal factors. For a firm that initially allocates the available funds for research equally between internal and external sources of knowledge, an increase in its innovative target should lead to an increased focus on the exploitation of external sources of knowledge. However, if the firm's innovative goals are too ambitious and hence its knowledge target is too high, exploiting external sources of knowledge appears to be a suitable short-term strategy but may not be effective in the long run. Another factor influencing the fund allocation decision is the cost of R\&D projects. For a firm with a relatively low cost of $R \& D$, external sources may not be effective anymore, since $\mathrm{R} \& \mathrm{D}$ projects are cheaper and thus create higher returns comparing to the external sources of knowledge.

In a highly competitive environment, which forces firms to introduce new products, focusing on the external knowledge acquisition is a highly efficient strategy for high R\&D intensity firms. For low R\&D intensity firms who spend less than $50 \%$ of their available funds on their in-house R\&D activities, the strategy of focusing primarily on external knowledge sources and seeking numerous collaborative agreements requires a very careful assessment. A short-sighted policy of exploiting mostly external knowledge, without taking into account the firm's absorptive capacity level, may prevent a firm from ever reaching its expected innovative goals, even if there are some temporary improvements in the beginning.

The findings of this research could also be used as normative suggestions for decision makers. Although this research provides the general insights for policy makers, there is still a need for a customized model that is based on the specific characteristics of a biotechnology firm in order to develop effective policies.

\section{References}

1. Ameri, F., Dutta, D.: Product lifecycle management: Closing the knowledge loops. Computer-Aided Design and Applications 2(5), 577-590 (2005) 
2. Awazu, Y., Baloh, P., Desouza, K.C., Wecht, C.H., Kim, J., Jha, S.: Information communication technologies open up innovation. Research-Technology Management 52(1), 5158 (2009)

3. Brem, A., Voigt, K.I.: Integration of market pull and technology push in the corporate front end and innovation management-insights from the German software industry. Technovation 29(5), 351-367 (2009)

4. Cohen, W.M., Levinthal, D.A.: Absorptive capacity: A new perspective on learning and innovation. Administrative Science Quarterly 35, 128-152 (1990)

5. Cooper, R.G., Kleinschmidt, E.J.: New products: The key factors in success (1990)

6. Dangelico, R.M., Garavelli, A.C., Petruzzelli, A.M.: A system dynamics model to analyze technology districts' evolution in a knowledge-based perspective. Technovation 30(2), $142-153$ (2010)

7. De Luca, L.M., Verona, G., Vicari, S.: Market orientation and R\&D effectiveness in High - Technology firms: An empirical investigation in the biotechnology industry*. Journal of Product Innovation Management 27(3), 299-320 (2010)

8. Deeds, D.L.: The role of R\&D intensity, technical development and absorptive capacity in creating entrepreneurial wealth in high technology start-ups. Journal of Engineering and Technology Management 18(1), 29-47 (2001)

9. Forrester, J.W.: Principles of systems. Productivity Press, Cambridge (1968)

10. Galanakis, K.: Innovation process. make sense using systems thinking. Technovation 26(11), 1222-1232 (2006)

11. Garcia, R., Calantone, R., Levine, R.: The role of knowledge in resource allocation to exploration versus exploitation in technologically oriented organizations*. Decision Sciences 34(2), 323-349 (2003)

12. García-Muiña, F.E., Pelechano-Barahona, E., Navas-López, J.E.: Making the development of technological innovations more efficient: An exploratory analysis in the biotechnology sector. The Journal of High Technology Management Research 20(2), 131-144 (2009)

13. Hall, L.A., Bagchi-Sen, S.: A study of R\&D, innovation, and business performance in the canadian biotechnology industry. Technovation 22(4), 231-244 (2002)

14. Hall, L.A., Bagchi-Sen, S.: An analysis of firm-level innovation strategies in the US biotechnology industry. Technovation 27(1-2), 4-14 (2007)

15. Herstatt, C., Verworn, D.I.B.: "The Fuzzy front end" of innovation. Working paper no. 4 (2001)

16. http://plmtechnologyguide.com (retrieved)

17. http://www. cimdata.com/ (retrieved)

18. Kang, K.N., Lee, Y.S.: What affects the innovation performance of small and mediumsized enterprises (SMEs) in the biotechnology industry? an empirical study on korean biotech SMEs. Biotechnology Letters 30(10), 1699-1704 (2008)

19. Khilji, S.E., Mroczkowski, T., Bernstein, B.: From invention to innovation: Toward developing an integrated innovation model for biotech firms. Journal of Product Innovation Management 23(6), 528-540 (2006)

20. Khurana, A., Rosenthal, S.R.: Towards holistic "front ends" in new product development. Journal of Product Innovation Management 15(1), 57-74 (1998), doi:10.1016/S07376782(97)00066-0

21. Kim, J., Wilemon, D.: Strategic issues in managing innovation's fuzzy front-end. European Journal of Innovation Management 5(1), 27-39 (2002)

22. Koen, P., Ajamian, G., Burkart, R., Clamen, A., Davidson, J., D’Amore, R., Johnson, A.: Providing clarity and a common language to the fuzzy front end. Research-Technology Management 44(2), 46-55 (2001) 
23. Matusik, S.F.: An empirical investigation of firm public and private knowledge. Strategic Management Journal 23(5), 457-467 (2002)

24. Ming, X., Yan, J., Lu, W., Ma, D.: Technology solutions for collaborative product lifecycle management-status review and future trend. Concurrent Engineering 13(4), 311-319 (2005)

25. Nieto Antolín, M.: Bases para el estudio del proceso de innovación tecnológica en la empresa Universidad de León (2001)

26. Niosi, J.: Explaining rapid growth in canadian biotechnology firms [electronic resource]. Statistics Canada. Science and Technology Redesign Project, Ottawa (2000)

27. Rasmus, D.: Collaboration, content and communities: An update, May, 31. Giga Information Group. Inc. (2002)

28. Reid, S.E., de Brentani, U.: The fuzzy front end of new product development for discontinuous innovations: A theoretical model. Journal of Product Innovation Management 21(3), 170-184 (2004)

29. Schroeder, R.G., Bates, K.A., Junttila, M.A.: A resource - based view of manufacturing strategy and the relationship to manufacturing performance. Strategic Management Journal 23(2), 105-117 (2002)

30. Stark, J.: Product lifecycle management: 21 st century paradigm for product realisation(decision engineering series) (2005)

31. Todtling, F., Trippl, M.: Knowledge links in high-technology industries: Markets, networks or milieu? the case of the vienna biotechnology cluster. International Journal of Entrepreneurship and Innovation Management 7(2), 345-365 (2007)

32. Traore, N.: Canadian biotech firms' creative capacity: On the role of absorptive capacity, relational capital, learning, and firm characteristics. International Journal of Biotechnology 6(1), 1-19 (2004)

33. Van Moorsel, D., Cranfield, J.A.L., Sparling, D.: Factors affecting biotechnology innovation in canada: Analysis of the 2001 biotechnology use and development survey. International Journal of Biotechnology 9(1), 39-59 (2007)

34. Verworn, B.: A structural equation model of the impact of the "fuzzy front end" on the success of new product development. Research Policy 38(10), 1571-1581 (2009), doi:10.1016/j.respol.2009.09.006

35. Zhang, Q., Doll, W.J.: The fuzzy front end and success of new product development: A causal model. European Journal of Innovation Management 4(2), 95-112 (2001) 